DOI: https://doi.org/10.30749/2594-8261.v1n1p153-163

\title{
ECOS DO MOVIMENTO DA NEGRITUDE NAS LITERATURAS AFRICANAS DE LÍNGUA PORTUGUESA
}

\section{ECHO OF THE NEGRITUDE MOVEMENT IN AFRICAN LITERATURES OF PORTUGUESE LANGUAGE}

\author{
Vanessa Ribeiro Teixeira ${ }^{1}$
}

\begin{abstract}
Resumo: Os anos 30 do século XX são marcados pelo surgimento do movimento da Negritude, articulado por estudantes negros, dentro e fora da África, que propunham repensar o lugar e o valor da cultura negra no mundo, através de uma escrita pontualmente crítica de cariz social, filosófico e político. Responsáveis pela publicação das Revistas Légitime Défense (1932), L'Étudiant Noir (1934) e Présence Africaine (1947-1968), esses pensadores "intencionam unir-se pela afirmação da cultura negra, para a conscientização do negro sobre sua própria condição" (SANTILLI, 1985, p. 174). Entre os diversos estudiosos das Literaturas Africanas de Língua Portuguesa, é importante considerar o impacto das novas formas de olhar para o devir histórico e a significação cultural da população negra, na África e na diáspora, que culminaram no Movimento da Negritude francófona e suas releituras, sobre a construção de uma literatura autenticamente africana nas colônias portuguesas. A poesia, sobretudo, a partir do final dos anos 40 do século $\mathrm{XX}$, reclama a possibilidade de trazer para o seu centro tanto o drama do homem negro colonizado quanto a valorização de sua cultura.
\end{abstract}

Palavras-chave: Movimentos sociais. Negritude. África francófona. África lusófona. Literaturas africanas.

Abstract: The thirties of twentieth century were marked by the emergence of the Negritude Movement, articulated by black students, inside and outside Africa, who proposed to rethink the place and value of black culture in the world, through a critical writing of a social, philosophical and political nature. Responsible for the publication of the journals Légitime Défense (1932), L'Étudiant Noir (1934) e Présence Africaine (1947-1968), these thinkers "intend to be united by the affirmation of the black culture, to the black's awareness of his own condition" (SANTILLI, 1985, p. 174). Among the many researchers of African Portuguese-language Literature, it is important to consider the impact of the new ways of looking at the historical development and the cultural significance of the black population, in Africa and in the diaspora, which culminated in the French-speaking Negritude Movement and its rereading, about the construction of an authentically African literature in the Portuguese colonies. The poetry, especially, from the late of the fortieths of twentieth

${ }^{1}$ Professora Adjunta do Setor de Literaturas Africanas de Língua Portuguesa da Universidade Federal do Rio de Janeiro. 
century, claims the possibility of bringing to its center both the drama of colonized black people and the valorization of their culture.

Keywords: Social movements. Negritude. French-speaking Africa. Portuguesespeaking Africa. African literature. 


\section{INTRODUÇÃO}

Demasiadamente longo foi o caminho percorrido para a formulação de iniciativas destinadas a repensar o lugar do negro na História e do Mundo. A modernidade europeia dos séculos XV e XVI alicerçou-se no desmantelamento progressivo de civilizações inteiras e diversos complexos culturais, sobretudo na África, mas também na Ásia e nas Américas. Estima-se que, entre 1450 e 1500, cerca de 150 mil escravos negros tenham sido capturados. Uma outra modernidade, dessa vez entre os séculos XVIII e XIX, sustentada pela filosofia iluminista e sedimentada pela Revolução Industrial, ao mesmo tempo em que proclama "Liberdade, Igualdade, Fraternidade", recoloca a África no centro das "negociações comerciais".

Desenrolam-se, assim, uma série de acordos que preveem uma distribuição mais "igualitária" do território e dos braços africanos. Dois dos exemplos mais emblemáticos são: 1) o Tratado de Ultrecht (1713), no qual Inglaterra e Espanha concordam em introduzir escravos nas possessões espanholas (4800/ano). Cerca de 94 anos depois, em 1807, a Inglaterra extingue o tráfico de suas colônias - uma das "moedas de troca" era, provavelmente, a participação "voluntária" dos negros na tropa que resistia ao avanço de Napoleão -, e começa a pressionar outras potências europeias a fazerem o mesmo; 2) a Conferência de Berlim (1884-1885), durante a qual Inglaterra, França, Alemanha e outros países concordam em ocupar regiões diversas do continente africano. França, Inglaterra e Alemanha já dispunham de importantes possessões, tendo-se lançado na defesa do território que mais condizia com seus interesses.

Embora estivéssemos ainda longe de uma construção intelectual e social que colocasse em xeque o lugar de subalternidade extrema a que o negro escravizado foi relegado, algumas iniciativas, ainda que sob a égide do protecionismo religioso colonial, dão alguns passos visando minimizar o aviltamento do homem negro. Em 1818, por exemplo, o juiz Bushrod Washington, da Suprema Corte norte-americana, apoia o primeiro grande retorno de negros escravizados para a África, movimento denominado "American Society for Colonizing the free People of Color". O direcionamento filosófico do movimento era inspirado nas ideias do 
Reverendo Robert Finley que entendia que a situação do negro norte-americano melhoria na medida em que eles retornassem para o lugar onde Deus os tinha criado.

\section{DESENVOLVIMENTO}

Antes de aprofundarmos a leitura sobre os pressupostos teórico-filosóficos basilares do Movimento da Negritude, parece-nos relevante dedicar algumas linhas para os seus antecedentes históricos. Ao longo do século XIX, outros movimentos de retorno à "terra-mãe África" foram organizados, sobretudo a partir das regiões dos Estados Unidos da América. Essas iniciativas tornam a América do Norte um dos principais redutos intelectuais, ainda no século XIX, voltados para repensar a importância da identidade cultural do negro no mundo. Em 1863, em resposta à situação paradoxal em que a sociedade norte-americana vivia (incentivo ao retorno de negros à África X sistema escravocrata), ocorre a emancipação dos escravos nos EUA. Pouco mais de trinta anos depois, em 1896, vem a público The supression of the African slave trade, importante publicação de Willian Burghardt Du Bois (18681963), então com 28 anos. Em 1903, publica-se As almas da gente negra, do mesmo autor. As obras - responsáveis ora por lançar um novo olhar sobre o processo de comércio de escravos, que sustentou a economia europeia por mais de quatro séculos, ora por propor uma forma de ser negro que atravessa fronteiras e percursos históricos - terão, certamente, influenciado as reflexões de pensadores como Sylvester Willians, advogado antilhano (Antilhas Britânicas) que parece ter cunhado o termo "pan-africanismo", proferido na I Conferência Pan-Africana, realizada em 1900, em favor dos negros colonizados. Du Bois, participante da Conferência, declara: "Naturalmente, a África é a minha pátria".

O conceito de Pan-africanismo está atrelado à constatação, ao mapeamento e à reflexão sobre as relações entre a África e o mundo, pontuando, sobretudo, as pontes históricas (ainda que trágicas), culturais e intelectuais que "irmana" os negros do/no continente africano e da/na diáspora. Dr. Du Bois prossegue na criação de espaços de debate e promoção da filosofia pan-africanista. Um passo importante, nesse sentido, foi a fundação da Associação Nacional para a Promoção das Gentes 
de Cor, que irá se tornar, anos mais tarde, o cerne filosófico do "Black Renaissance". O arauto dessa proposta será, sem dúvidas, o poeta norte-americano Langhston Hughes, idealizador do "Harlem Renaissance" e autor do poema "The Negro Speaks of Rivers" (1921), um grito sobre a história trágica do negro na diáspora, mas também uma ode à valorização da identidade e da cultura negras.

Uma série de congressos voltados para o debate sobre o pan-africanismo foi realizada no eixo EUA-Europa, após o fim da Primeira Guerra Mundial: Paris (1919), Londres e Bruxelas (1921), Londres e Lisboa (1923) e Nova Iorque (1927). Aliás, o desenrolar e o desfecho das duas Grandes Guerras, sobretudo a Segunda, facultou aos intelectuais preocupados com a reconstrução de um lugar de autonomia para os negros no mundo a possibilidade de formular novas perspectivas sociais, culturais e, finalmente, políticas para o povo negro. Apesar da precedência de Dr. Du Bois cujo volume Almas Negras (ao qual já nos referimos) teria influenciado o Renascimento Negro dos anos 20 e 40 -, podemos destacar outros nomes fundamentais para a reconstituição das raízes dos ideais da Negritude. Os pressupostos filosóficos do humanista, diplomata, historiador, sociólogo e médico haitiano, Jean Price-Mars, por exemplo, logram não só pensar a situação do negro, mas as relações entre os homens ao longo dos tempos. René Maran (1887-1960), escritor martiniquense, surpreende com a publicação do seu romance Batouala (1921), um ousado manifesto contra a colonização francesa em terras africanas.

Os anos 30 do século XX são marcados pela produção de estudantes negros, responsáveis pela publicação das Revistas Légitime Défense (1932), L'Étudiant Noir (1934) - segundo José Pires Laranjeira, 1935 - e Présence Africaine (1947-1968), as quais, de acordo com Maria Aparecida Santilli, no seu antológico Estórias Africanas (1985), "intencionam unir-se pela afirmação da cultura negra, para a conscientização do negro sobre sua própria condição" (SANTILLI, 1985, p. 174). Entre os principais nomes envolvidos nessa empreitada, devemos destacar o poeta, dramaturgo, ensaísta e político martiniquense, Aimé Césaire (1913-2008), a quem devemos a criação e aplicação do termo "negritude", surgido no longo poema Cahier d'um retour au pays natal, publicado na Revista Volontés 10, em 1939. Léon Damas (1912-1978), escritor, poeta e político, nascido na Guiana Francesa, e Leopold Sedar Senghor (1906-2001), escritor e político senegalês, completam essa que será 
considerada uma espécie de Santíssima Trindade do Movimento da Negritude Francófona nos anos 30.

Aprendemos com Kabengele Munanga (1988) que, entre os principais objetivos do movimento, cabe destacar: 1) buscar o desafio cultural do mundo negro ("identidade negra"); 2) protestar contra a ordem colonial e 3) lutar pela emancipação de seus povos oprimidos, conclamando a civilização do universal (MUNANGA, 1988, p. 43-44). No entanto, apesar da urgência e da legitimidade desses objetivos, o movimento sofreu duras críticas posteriores, formuladas por intelectuais que se tornariam grandes estudiosos das relações coloniais. Essas críticas demonstravam, muitas vezes, a insatisfação desse grupo de jovens intelectuais, situados no eixo afro-americano, diante de construções dicotômicas promulgadas, principalmente, por Senghor, para quem a razão estava para a Europa, assim com a emoção estava para a África. Tal leitura da projeção da África no mundo, apesar de apaixonada, reverbera o lugar-comum do discurso colonial que, ao longo de séculos, desprovia o continente de razão, justificando o domínio que Ihe fora imposto. São pontuais as invectivas contra a Negritude, declaradas por Wole Soyinka, da Nigéria ("o tigre não precisa declarar a sua tigretude"), ou do sociólogo daomeano Stanislas Adotevi ("forma branca de ser negro").

Por outro lado, encontramos em Frantz Fanon (1925-1961), psiquiatra e ensaísta martiniquense, e em Albert Memmi, pensador tunisiano, escritos que se tornaram clássicos entre os estudos sobre as relações coloniais e sua construção discursiva. São da autoria de Fanon os emblemáticos Pele negra, máscaras brancas (1952), Os condenados da terra (1961) e Pela Revolução Africana (1964), obras que mapeiam o discurso que, ao longo de séculos, logrou subjugar o povo negro, a fim de dominar-lhe a terra e a força braçal. Por seu turno, Memmi, com seu Retrato mítico do colonizado precedido do Retrato mítico do colonizador (1973), amplamente inspirado na obra de Fanon, analisa a criação e recriação de mitos justificadores da exploração colonial.

Críticas à parte, entendemos, junto a inúmeros estudiosos das Literaturas Africanas de Língua Portuguesa, importante considerar o impacto das novas formas de olhar para o devir histórico e a significação cultural da população negra, dentro e fora da África, que culminaram no Movimento da Negritude francófona e suas 
releituras, sobre a construção de uma literatura autenticamente africana nas colônias portuguesas. A poesia, sobretudo a partir do final dos anos 40 do século XX, reclama a possibilidade de trazer para o seu centro tanto o drama do homem negro colonizado quanto a valorização de sua cultura. Segundo Patrick Chabal (1994),

[embora] nas colônias africanas portuguesas a negritude nunca tenha tomado a forma amplificada e exaltada que assumiu no império francês, houve um processo semelhante, mesmo que não tenha havido 'influência direta'. A negritude é, dessa forma, a mais explícita e manifesta fase de nacionalismo cultural que se pode encontrar na literatura africana moderna (CHABAL, 1994, p. 55).

O centro de efervescência e recepção dos postulados da Negritude pelos futuros poetas e prosadores das Literaturas Africanas de Língua Portuguesa foi, em grande medida, a famosa CEI (Casa dos Estudantes do Império). Hospedagem para os estudantes oriundos das terras de Portugal "no Ultramar" e centro de observação e controle - ou da "tentativa de" - de toda uma intelectualidade perigosamente em formação, a CEI logrou tornar-se uma espécie de "ninho de serpentes". Nesse caso, a "surucucu, cobra maldita" (RUI, 1985) morderia as bases discursivas e literárias do próprio sistema colonial. Carlos Everdosa, no seu Itinerário da Literatura Angolana (1972), identifica os jovens estudantes angolanos, por exemplo, reunidos em diversas associações culturais, em Angola e Portugal, como intelectuais "fortemente impressionados pelas correntes neo-realistas da literatura, do cinema e da pintura, triunfantes no pós-guerra, e mais tarde não só pela descoberta da negritude que desde 1935 vinha sendo propugnada por Senghor e Césaire, mas também pelo exemplo de escritores negros norte-americanos (...) e do cubano Nicolas Guillén" (EVERDOSA, 1972, p. 94-95).

Seja de maneira recorrente ou em raras composições, diversos poetas, sobretudo angolanos, moçambicanos e santomenses, trouxeram para os seus escritos o novo sopro de vida à cultura africana proclamado pela Negritude. Francisco José Tenreiro, tem participação fulcral nesse processo, visto que, entre seus pronunciamentos na Assembleia Nacional Portuguesa - representando São Tomé e Príncipe - e a escrita poética, logra trazer as discussões em torno da Negritude para os espaços africanos sob colonização portuguesa. Ao lado de Mário 
Pinto de Andrade, organiza a coletânea Poesia negra de expressão portuguesa (1953). Mário Pinto de Andrade é enfático ao, na "Apresentação" da coletânea, evidenciar o protagonismo de Tenreiro dentro do universo da Negritude em língua portuguesa:

Quem pela primeira vez exprimiu a 'negritude' em língua portuguesa foi sem sombra de dúvida Francisco José Tenreiro no seu livro Ilha de Nome Santo, datado de 1942. Devemos assinalar que ele encontrou por si, individualmente, as formas mais autênticas de expressão subjectiva e objectiva da 'negritude'. A llha de Nome Santo aparece assim como um feliz encontro dos temas da sua terra de origem ( $\mathrm{S}$. Tomé) e ainda como exaltação do homem negro de todo o mundo (ANDRADE; TENREIRO, 2012, p. 16).

Como uma via de mão dupla, os postulados do Renascimento Negro, da Negritude Francófona e do Negrismo Americano influenciam a produção intelectual e literária de autores da África Lusófona, mas, surpreendentemente, uma contrapartida também é possível. É digna de nota, por exemplo, a dedicatória do poema "La machine Singer", do poeta haitiano René Depestre, dirigida à Mário Pinto de Andrade. Através da leitura poética da máquina, Depestre metaforiza todas as formas de opressão por ela representadas, incluindo o drama do colonizado da África de domínio português.

Pires Laranjeira (1995) identifica nos poetas africanos - dos anos 40 e de épocas posteriores - uma espécie de Negritude latente, marcada pela escolha de novos temas e novas geografias para a poesia. Em Literaturas Africanas de Expressão Portuguesa, ao pensar a negritude de Agostinho Neto, afirma:

(...) é notória a referência concreta a elementos da realidade geográfica, histórica e cultural, a demarcação de um espaço físico, a criação de uma cosmovisão e de um imaginário africanos, a recusa da subjetividade, da abstração e do intimismo. Essa é a via da sua aproximação ao modo narrativo (da tradição ancestral ou da ocidental), numa luta desesperada contra a tradição do lirismo português e ibérico, em busca da fundação do discurso de uma nova nacionalidade literária na língua portuguesa (LARANJEIRA, 1995, p. 94). 
Diante do poema "Confiança", de Agostinho Neto (1985), por exemplo, parece-nos inegável a proposta de uma nova orientação para conceber o valor do homem negro no mundo:

\author{
(...) \\ E do drama intenso \\ duma vida imensa e útil \\ resultou certeza \\ As minhas mãos colocaram pedras \\ nos alicerces do mundo \\ mereço o meu pedaço de pão \\ (AGOSTINHO NETO, 1985, p. 41)
}

Da costa índica africana, nascem Noémia de Sousa e José Craveirinha, poetas moçambicanos que melhor e mais frequentemente traduziram em poesia os ideais negritudinistas, sobretudo no que diz respeito à valorização das culturas nascidas no ventre da "terra-mãe África". Em seus escritos, Noémia mergulhava numa poesia oscilante entre ideias neo-realistas e negritudinistas, apesar de declarar desconhecer a Negritude francófona quando escreveu os 43 poemas reunidos em Sangue Negro. Para Pires Laranjeira, sua negritude é "intuitiva", visto que

(...) a específica situação colonial de Moçambique, mais dada à discriminação racial do que Angola, e o seu conhecimento da língua francesa e inglesa, permitiram que as mesmas fontes (Black Renaissance, Indigenismo haitiano e Negrismo cubano), associadas à divulgação do Neo-realismo e do Modernismo em Moçambique, originassem um discurso de Negritude (...) (LARANJEIRA, 1995, p. 269-270)

De forma semelhante, entendemos a mensagem de "Samba", cujos versos oscilam entre o deslumbramento diante da grandeza estética e da força de resistência dos ritmos produzidos pelos negros no mundo, pontualmente o jazz e o samba...

\footnotetext{
$(\ldots)$

o súbito bater de jazz

soou como um grito de libertação,
} 
como uma lança rasgando o papel celofane das composturas forçadas.

(SOUSA, 2016, p. 85)

e a consciência sobre situação de opressão experimentada também pelos negros:

\section{(...) \\ Oh ritmos fraternos do samba!}

Acordando o meu povo adormecido à sombra dos imbondeiros, dizendo na sua linguagem encharcada de ritmos que as correntes dos navios negreiros não morreram, não, só mudaram de nome,

mas ainda continuam, continuam, oh ritmos fraternos do samba! (SOUSA, 2016, p. 85-86)

"Manifesto", de José Craveirinha, torna-se um poema emblemático, podendo mesmo ser entendido como uma espécie de "arte poética" dos postulados da Negritude na literatura de língua portuguesa. Entre a saudação da beleza do homem negro africano e a exaltação da Mãe África, a metaforização lírica das agruras da colonização:

Oh!

Meus belos e curtos cabelos crespos e meus olhos negros como insurrectas grandes luas de pasmo na noite mais bela das mais belas noites inesquecíveis das terras do Zambeze.

Oh! Meus dentes brancos de marfim espoliado puros brilhando na minha negra reencarnada face altiva e no ventre maternal dos campos da nossa indisfrutada colheita de milho o cálido encantamento selvagem da minha pele tropical.

Ah, Mãe África no meu rosto escuro de diamante de belas e largas narinas másculas frementes haurindo o odor florestal $e$ as tatuadas bailarinas macondes

nuas

na bárbara maravilha eurrítmica

das sensuais ancas puras

e no bater uníssono dos mil pés descalços.

(CRAVEIRINHA, 2010, p. 24-26) 
Ao longo da leitura dos versos do Velho Cravo, parece-nos impossível não ouvir os gritos apaixonados de Leopold Sédar Senghor dirigidos para uma MãeMulher-África, adorada naquilo que ainda possa guardar de mais "selvagem" e "primitivo". Entre o Movimento da Negritude e as Literaturas Africanas de Língua Portuguesa, novas formas de escrever a história, a cultura e o homem negro são criadas.

\section{REFERÊNCIAS}

ANDRADE, Mario Pinto de; TENREIRO, Francisco José. Poesia negra de expressão portuguesa. Vila Nova de Cerveira: Nóssomos, 2012. (Edição Fac-similada)

CHABAL, Patrick. Vozes moçambicanas. Lisboa: Vega, 1994.

CRAVEIRINHA, José. Antologia poética. Organização de Ana Mafalda Leite. Belo Horizonte: Editora UFMG, 2010.

EVERDOSA, Carlos. Itinerário da Literatura Angolana. Luanda: Editorial Culturang, 1972.

LARANJEIRA, José Pires. Literaturas africanas de expressão portuguesa. Lisboa: Universidade Aberta, 1995.

MUNANGA, Kabengele. Negritude: usos e sentidos. 2 ed. São Paulo: Ática, 1988.

AGOSTINHO NETO, António. Sagrada esperança. Rio de Janeiro: Ática, 1985.

RUI, Manuel. Eu e o outro... o invasor ou em poucas três linhas uma maneira de pensar o texto. Disponível em: <http://ricardoriso.blogspot.com.br/2007/10/eu-e-ooutro-o-invasor-ou-em-poucas-trs.html>. Acesso em: 20 nov. 2017. Comunicação apresentada no Encontro Perfil da Literatura Negra. São Paulo, Brasil, 23 maio 1985.

SANTILLI, Maria Aparecida. Estórias africanas: história e antologia. São Paulo: Ática, 1985.

SOUSA, Noémia de. Sangue negro. São Paulo: Editora Kapulana, 2016. 